\title{
O debate desenvolvimentista: reflexões sobre alternativas desenvolvimentistas marxistas
}

\author{
The developmental debate: reflections on \\ Marxists developmental alternatives
}

MARIA DE LOURDES ROLLEMBERG MOLLO*

\begin{abstract}
RESUMO: Este artigo examina o desenvolvimentismo, explicando por que certas proposições pós-keynesianos devem ser aceitas a partir de uma perspectiva marxista, e o que deve ser modificado dentro da antiga abordagem, a fim de cumprir um papel transformador na sociedade. Também contrasta criticamente os pontos de vista marxista e pós-keynesianos dos papeis do Estado e do mercado, a fim de justificar políticas alternativas para transformar sociedades capitalistas.
\end{abstract}

PALAVRAS-CHAVE: desenvolvimentismo; marxismo; pós-keynesianismo.

ABASTRACT: The developmentalism debate. This article examines developmentalism, explaining why certain post-Keynesian propositions should be accepted from a Marxist perspective, and what should be modified within the former approach in order to fulfill a transformative role in society. It also critically contrasts the Marxian and post-Keynesian views of the roles of the state and the market, in order to justify policy alternatives to transform capitalist societies.

KEYWORDS: developmentalism; Marxism; Post-Keynesianism.

JEL Classification: B51; O10; P20; P30.

\section{INTRODUÇÃO}

O objetivo deste artigo é discutir o desenvolvimentismo do ponto de vista marxista. Vários têm sido os trabalhos recentemente publicados sobre esse assunto, a partir da iniciativa de Bresser-Pereira (1991), a quem devemos a retomada da discussão das políticas de desenvolvimento como alternativa ao neoliberalismo. Em geral esses trabalhos partem de um marco teórico pós-keynesiano estruturalista (Bresser-Pereira, 2004, 2006, 2007 e 2011; Carneiro, 2006 e 2012; Sicsú et al,

\footnotetext{
* Professora titular do Departamento de Economia da Universidade de Brasilia. E-mail: mlmollo@unb. br. Submetido: 22/janeiro/2014: Aprovado: 9/outubro/2014.
} 
2005). Críticas à esquerda também têm sido apresentadas às propostas, chamando a atenção, em especial, para a ineficácia das políticas desenvolvimentistas e para o caráter não transformador das propostas novo-desenvolvimentistas (Fiori, 2011, 2012a; 2012b). Este artigo procura apresentar um ponto de vista alternativo.

Para isso, por um lado, destaca o progresso oferecido pelo novo-desenvolvimentismo, com relação ao neoliberalismo, e chama a atenção para a sua importância em qualquer transformação progressista da sociedade. Reconhece, porém, a filiação teórica principal das propostas desenvolvimentistas no pós-keynesianismo, chamando atenção para a complementações necessárias a uma proposta de fato transformadora nos termos de Marx. A ideia, portanto, é responder ao porquê de aceitar a proposta desenvolvimentista pós-keynesiana, mesmo dentro da abordagem marxista, e o que alterar nela para que cumpra seu papel transformador da sociedade.

De forma a argumentar em torno desses assuntos, o artigo começa com uma seção destinada a definir o desenvolvimentismo, em particular no que se refere à atuação do Estado, destacando algumas diferenças internas de concepções, e acordos e desacordos entre desenvolvimentistas. É o que será feito na primeira sessão, logo após esta introdução.

Em seguida, a segunda sessão será dedicada a responder o que deve ser alterado ou incluído na abordagem marxista, com relação à pós-keynesiana. O papel do Estado na concepção marxista é discutido, assim como são enfrentadas algumas divergências no interior do próprio marco teórico, de forma a justificar as medidas a serem apresentadas. A abordagem assumida é aí justificada, quanto ao papel do Estado na concepção desenvolvimentista defendida. A ideia é a de argumentar sobre as consequências que tal papel do Estado tem sobre a inserção do trabalhador na relação capital-trabalho.

$\mathrm{Na}$ terceira sessão, pós-keynesianos e marxistas são confrontados sobre as razões diferentes pelas quais lutam pelo desenvolvimentismo, delimitando os aspectos convergentes e divergentes de suas proposições, as primeiras na defesa do capitalismo e a outra buscando preparar as condições para sua transformação.

Finalmente, na quarta sessão, são elencadas as medidas necessárias, ao longo da proposta desenvolvimentista, para garantir as condições gerais fundamentais para a transformação da sociedade capitalista numa melhor. Ao final do trabalho são elencadas algumas considerações finais.

\section{O DESENVOLVIMENTISMO: PÓS-KEYNESIANOS E MARXISTAS}

As análises desenvolvimentistas e novo-desenvolvimentistas não foram todas uniformes, nem tiveram origens teóricas únicas, nem mesmo as propostas foram sempre consensuais, o que explica a ideia central deste trabalho de justificar sua aceitação por duas matrizes teóricas diferentes. De fato, desde a abordagem estruturalista cepalina, há raízes teóricas mais keynesianas e outras mais marxistas (Prebisch, 1961; Frank, 1973; Marini, 1985, Furtado, 1969), ao tratar do desenvolvimento.

Mesmo nas versões mais atuais do chamado novo-desenvolvimentismo, há 
diferenças de ênfases nos vários fatores promotores do desenvolvimento (Bresser-Pereira, 1991, 2006, 2011; Sicsú, de Paula e Michel, 2005; Carneiro, 2006 e 2012; Mollo e Fonseca, 2013; Bielschowsky, 2012), e no que privilegiar como política na estratégia desenvolvimentista.

Em todas as versões, porém, a definição de desenvolvimentismo incorpora alguns argumentos que nos interessam particularmente destacar, que são a necessidade de intervenção estatal ativa e a busca por reduzir a pobreza e a desigualdade. De fato, se tomarmos a definição de Bielschowsky (1988, p. 7), o desenvolvimentismo pode ser definido como a "ideologia de transformação da sociedade brasileira". Ele se baseia em: um projeto econômico voltado à industrialização como via de superação da pobreza e do subdesenvolvimento; e na ideia de que não vem pela espontaneidade das forças de mercado, exigindo a atuação do Estado como indutor, agente planejador do desenvolvimento e/ou investidor direto. Para Fonseca (2004, p.226), há três elementos que sempre constituíram um "núcleo duro" comum às várias concepções de desenvolvimentismo: o da industrialização, o do intervencionismo pró-crescimento; e o do nacionalismo, delimitando o papel do capital estrangeiro e sempre o subordinando a um "projeto nacional". Finalmente, mesmo numa concepção mais ortodoxa, como a de Prebisch (1961, p. 14), a política de desenvolvimento (ou desenvolvimentismo) "significa um esforço deliberado de atuar sobre as forças da economia a fim de acelerar seu crescimento, não pelo crescimento mesmo, mas como meio de conseguir um melhoramento persistente da renda nos grupos sociais de rendas inferiores e médias e sua participação progressiva na distribuição da renda global". As ênfases são nossas para destacar o que buscamos em comum com o desenvolvimentismo.

Ou seja, trata-se de perceber e considerar importante, no que se chama desenvolvimentismo, o papel interventor do Estado como uma necessidade para alcançar a transformação da sociedade na direção de uma situação melhor, em particular, para o que interessa particularmente neste artigo, em termos de redução da pobreza e da desigualdade. Entre as diferenças, porém, no interior do desenvolvimentismo, cumpre destacar, neste artigo, três. A primeira relaciona-se com o papel do mercado interno ou externo para o crescimento econômico; a segunda está ligada à importância da desconcentração da renda dentro dos objetivos desenvolvimentistas e a terceira ao tipo de intervenção do Estado que se pretende. Quanto ao primeiro aspecto, todas as concepções desenvolvimentistas aceitam o crescimento do mercado interno. A diferença, porém, entre elas, é o papel da demanda interna como motor do crescimento, no primeiro caso, e como consequência do crescimento movido pelo mercado externo, no segundo. Nossa preferência pela primeira alternativa decorre de esperarmos que haja mais interesses em geral no desenvolvimento da demanda e, então, na necessidade de reduzir pobreza e desigualdade quando o modelo acha-se calçado na demanda interna, do que se ela é estimulada apenas como consequência do processo de crescimento baseado em outros fatores.

Além disso, como chama a atenção Bielschowsky $(2002,2012)$, as exportações atuam no Brasil como complemento à demanda interna, uma vez que as decisões de investir, nas empresas sediadas no Brasil, são tomadas com base na evolução do 
mercado interno. A dimensão potencial do mercado interno de consumo de massa representa, segundo o autor, "extraordinária oportunidade". A produção e o consumo de massa no país permitem aumentar os rendimentos de escala, o progresso técnico e permitem ainda a elevação dos salários. Chama ainda a atenção para os benefícios do aumento na produção industrial, aproveitando os encadeamentos produtivos da produção de bens finais de consumo popular, inclusive os de maior intensidade tecnológica, integrando de forma virtuosa crescimento e distribuição de renda. Daí por que considera o consumo de massa um dos três motores do desenvolvimento econômico, juntamente com os recursos naturais e a infraestrutura, todos eles podendo ser 'turbinados' pela formação de encadeamentos produtivos tanto nos setores tecnologicamente nobres quanto em setores produtivos tradicionais.

A esse respeito, conforme analisa Carneiro (2012), em algumas propostas novo-desenvolvimentistas o papel da melhoria da distribuição de renda é praticamente desconsiderado, ao contrário da proposta social-desenvolvimentista (Bielschowsky, 2001, 2012) que, conforme mencionado, atribui à redistribuição de renda e ao consequente consumo de massas um papel determinante do desenvolvimento.

Quanto ao papel do Estado, sabe-se que, para os pós-keynesianos, ele é todo-poderoso, enquanto para os marxistas o Estado é necessário no capitalismo, tem um papel ao qual não pode se furtar, mas não resolve todos os problemas, já que eles são inerentes à lógica de funcionamento do modo de produção. Além disso, mesmo no interior da teoria marxista do Estado, há divergências quanto ao seu papel que explicam por que os marxistas não são todos favoráveis à defesa do desenvolvimentismo como será o caso neste artigo.

Assim, se a filiação teórica pós-keynesiana dos desenvolvimentistas é clara, para os marxistas tudo depende da concepção de Estado e do seu papel, mais particularmente da influência do desenvolvimentismo na relação capital-trabalho, e de como garantir a transformação da sociedade ao longo do crescimento proposto pelo desenvolvimentismo. É o que analisaremos a seguir, começando por resenhar e discutir o papel do Estado nas concepções marxistas.

\section{O PAPEL DO ESTADO NAS CONCEPÇÕES MARXISTAS E A DEFESA DO DESENVOLVIMENTISMO.}

O Estado, na concepção marxista, é um Estado de classe, não havendo desacordo sobre isso. Ao contrário, todos concordam que o Estado, exatamente por isso, não está apto a fazer por si só nenhuma transformação que fuja à lógica do sistema. Aí, porém, acaba o consenso, e surgem particularmente duas correntes que se destacam desde o início dos anos 1970 no debate sobre o tema.

A primeira corrente apoia-se em Poulantzas (1971, p. 40), para quem o Estado é "fator de coesão" dos níveis econômico, político e ideológico, com função de regulação de equilíbrio global de uma formação social. Partindo dessa percepção, Poulantzas, todavia, vê uma autonomia relativa ou limitada do Estado com relação às classes, autonomia essa que permite que políticas estatais possam beneficiar os 
trabalhadores mesmo que o Estado, como Estado de classe, defenda o capitalismo como um todo e beneficie os trabalhadores sempre com o objetivo de garantir o próprio funcionamento do sistema.

As razões para tal autonomia relativa são várias, destacando-se em particular, a nosso ver, o fato da relação do Estado com a sociedade não se confundir com a relação de exploração, embora possa beneficiá-la e protegê-la (Brunhoff, 1977, 1982; Mollo, 2001, 2013). Além disso, como o próprio Poulantzas menciona, no interior do aparelho de Estado encontram-se classes e frações diversas de classes, o que é outro argumento importante para justificar a relatividade da autonomia mencionada.

Para a outra concepção, defendida por Miliband (1973, p. 87), porém, tal autonomia, mesmo relativa, não existe, uma vez que a dominação política do capital está ligada à monopolização do poder político e econômico. O Estado é, pois, o braço da burguesia, e o papel nas transformações é todo da luta de classes, não se podendo contar com o Estado.

A partir dessas duas visões, a discussão marxista se desenvolve e forma seguidores cujas posições continuam se opondo, em particular no que se refere ao assunto tratado neste artigo, qual seja, se é possível e se interessa contar com as políticas estatais para beneficiar os trabalhadores, o que justificaria o apoio ao desenvolvimentismo em oposição ao neoliberalismo, ou se isso não faz sentido, o que tornaria o desenvolvimentismo uma proposta não defensável.

Destacam-se como exemplares as opiniões de dois seguidores, respectivamente, das posições de Poulantzas e Miliband. Por um lado, temos Jessop (1991), para quem "enquanto o keynesianismo era a expressão ideológica da tentativa do capital e do Estado de responder a aspirações generalizadas da classe trabalhadora no boom do pós-guerra, o neoliberalismo é a expressão ideológica da subordinação das aspirações da classe trabalhadora à valorização do capital”. De outro, temos Holloway (1991), que pensa que a estratégia de retração do Estado pode ter poder desestabilizador interessante para a mudança. Ou seja, os problemas provocados pelo liberalismo econômico, poderiam ajudar a acabar com o capitalismo.

A esse respeito nossa posição é que é preciso contar com as políticas estatais para melhorar a inserção dos trabalhadores na relação capital-trabalho (Mollo, 2002, 2012). Só dessa forma é possível mais que melhorar as condições de vida do trabalhador - o que por si só já é muito importante -, ainda, por meio dessa melhoria, garantir que ele tenha melhores condições de se organizar e de se preparar para a autogestão da sociedade transformada. A esse respeito é importante destacar que, após o debate acalorado apenas aqui sumariado, que teve lugar nos anos 1970, um grupo de pesquisadores remanescente dos debates, The London-Edinburgh Weekend Return Group (LEWRG), publica, em 1979, um panfleto intitulado "In and Against the State", em que o Estado é analisado como opressor mas, em nova edição (LEWRG, 1980), publica também um Poscript. Neste, chegam à conclusão que reforça a nossa de que, já no início do neoliberalismo (de Thatcher) houve perdas para os trabalhadores. Ora, isso, por um lado, piora sua 
posição na relação capital-trabalho a curto prazo e, por outro, leva a perda do poder de organização da classe, piorando a sua situação também no futuro. Como destaca o próprio London-Edinburgh Weekend Return Group (1980), embora condenando a nostalgia com relação ao keynesianismo, pelo menos ele criava espaço, "[...] ao menos uma base a partir da qual organizar a ação coletiva" (Lewrg, 1980, p. 123).

O aumento do emprego e do salário, com o crescimento, melhora a posição relativa do trabalhador na relação capital-trabalho e amplia o poder do trabalhador não apenas imediatamente contra o capital, mas para se preparar para assumir o processo de produção e as transformações necessárias do capitalismo. Nesse sentido, não há dúvidas, por exemplo, quanto aos ganhos para a classe trabalhadora obtidos no segundo governo Lula, completamente diferentes dos obtidos nos períodos anteriores. Os aumentos de salário mínimo em geral e os ganhos proporcionados pelos programas relacionados à previdência e assistência social, como é o caso do Benefício de Prestação Continuada (BPC); o Bolsa Família; o aumento do salário médio com a retomada do crescimento da produção e do emprego e o aumento da formalização do trabalho, com a redução consequente da desigualdade caminham na direção correta se o que se quer é preparar a sociedade para ser transformada.

A preparação da sociedade ou das condições para a transformação da sociedade é algo fundamental porque, como observado pelo próprio Marx em frase famosa,

"Uma formação social nunca decai antes de estarem desenvolvidas todas as forças produtivas para as quais é suficientemente ampla, e nunca surgem relações de produção novas e superiores antes de as condições materiais de existência das mesmas terem sido chocadas no seio da própria sociedade velha. Por isso a humanidade coloca sempre a si mesma apenas as tarefas que pode resolver, pois que, a uma consideração mais rigorosa, se achará sempre que a própria tarefa só aparece onde já existem, ou pelo menos estão no processo de se formar, as condições materiais da sua resolução" (Marx, 1859, p. 547).

Por outro lado, a mudança do capitalismo não se fará da noite para o dia, mas será construída como movimento processual a partir do que existe no capitalismo. Até lá é preciso: melhorar a posição do trabalhador na relação capital-trabalho, para fortalecê-lo e permitir que se organize melhor; assim como para preparar as condições estruturais a serem desenvolvidas na mudança. Nesse sentido, por um lado, busca-se o desenvolvimentismo no sentido de garantir a intervenção estatal para estimular o crescimento da renda e do emprego. Por outro, busca-se transformar a sociedade no sentido de construir uma estrutura mais igualitária não apenas com relação à renda, mas com relação às oportunidades e ao poder de decisão. Sobre isso falaremos no próximo item. 


\section{CONFRONTANDO DESENVOLVIMENTISTAS E MARXISTAS}

A aceitação do desenvolvimentismo pelos marxistas, justificada nas duas sessões anteriores, requer, todavia, clareza sobre as diferenças teóricas com relação aos demais partidários do desenvolvimentismo, porque esses últimos, ao contrário de Marx e dos marxistas, são defensores do capitalismo. Em particular, é preciso comparar com os pós-keynesianos, para quem o Estado tem papel fundamental no desenvolvimento.

A esse respeito duas críticas ao capitalismo se destacam logo no início de $O$ Capital: o caráter mercantil da produção capitalista e a exploração envolvida na geração do lucro. Ao contrário dos demais defensores do desenvolvimentismo, essas críticas precisam ser enfrentadas desde o início, de forma a haver clareza sobre os limites do próprio desenvolvimentismo como estratégia de transformação e o que propor como alternativas e complementações de fato transformadoras, dentro de uma abordagem marxista.

Embora a crítica à exploração seja a mais assumida e mais conhecida, a crítica ao caráter mercantil é menos consensual, mesmo entre os marxistas, mas é fundamental para bem desenhar alternativas transformadoras, em particular no que se refere ao que esperar e como conduzir a intervenção estatal.

Para enfrentar a questão da exploração, Marx referiu-se algumas vezes ao sistema de produção cooperativo. A esse respeito, dizia:

"The cooperative factories run by workers themselves are, within the old form, the first examples of the emergence of a new form, even though they naturally reproduce in all cases, in their present organization, all the defects of the existing system, and must reproduce them. But the opposition between capital and labour is abolished there, even if at first only in the form that the workers in association become their own capitalist, i. e., they use the means of production to valorise their labour. These factories show how [...] a new mode of production develops and is formed naturally out of the old" (Marx, 1974, pp. 571-2).

No capitalismo, a concorrência é vista como fundamental para dar eficiência aos mercados, e isso é compartilhado tanto por neoclássicos, novos clássicos e novos keynesianos quanto pelos pós-keynesianos mais heterodoxos. Para os marxistas, ao contrário, o resultado da concorrência é a concentração e a centralização do capital, embora se observem contratendências que atrasam ou dificultam esses processos. De fato, dado o objetivo de lucro, o conflito intercapitalista, por meio da concorrência, conduz a que todo capitalista busque obter cada vez mais lucros, o que ocorre principalmente por meio de avanços tecnológicos que aumentam a produtividade do trabalhador e barateiam as mercadorias produzidas. Esse barateamento faz com que os custos, quando comparado aos custos médios, na base dos quais as mercadorias são vendidas, deem origem a superlucros. Todos os capitalistas agem dessa forma, mas apenas alguns são bem-sucedidos, uma vez que, 
mesmo buscando e alcançando ganhos de redução de custo, só os mais bem-sucedidos no processo de modernização do processo produtivo conseguem ficar em condições superiores às do custo médio, obtendo, por isso, superlucros. Quem tem superlucros num período tem mais condições de obtê-los nos períodos seguintes, porque pode usar os recursos para investir em pesquisa, e implementar mudanças tecnológicas mais avançadas. Daí por que é o sucesso na própria concorrência que leva à concentração e à centralização do capital. Esse processo, longe de beneficiar os trabalhadores, tem para eles consequências negativas. Por um lado, aumentando a sua produtividade reduz relativamente sua demanda, provocando desemprego tecnológico. Por outro, o desemprego consequente pressiona os salários para baixo. Finalmente, a própria concentração e centralização do capital implicam redução de tarefas como as administrativas, o que, além da tecnologia poupadora de mão de obra, contribui para aumentar o desemprego.

Assim, para os marxistas, é preciso substituir a concorrência pela cooperação. A ideia, nesse caso, é introduzir a cooperação, não apenas para eliminar ou preparar a eliminação da exploração do homem pelo homem no processo de produção, mas enquanto princípio a substituir a concorrência como princípio orientador do processo de produção. Assim, quaisquer que sejam os problemas, de resto conhecidos, de absorção do sistema cooperativo pela lógica capitalista, ainda assim é preciso insistir em empreendimentos cooperativos, seja para eliminar a oposição capital-trabalho no interior do próprio empreendimento, seja para disseminar uma lógica de comportamento diferenciada que prepara a sociedade para a transformação, seja para treinar o comportamento de gestão de forma cooperativa.

No capitalismo as decisões são tomadas individualmente e as políticas públicas são desenhadas olhando os indivíduos e não sua posição de classe. Para os marxistas, é preciso pensar em classes e não em indivíduos, ao conceber as políticas. Assim, não basta, como para os pós-keynesianos, que o Estado garanta o investimento que gera renda e emprego de forma multiplicada, mas é importante interferir no tipo de investimento a ser implementado, zelando para que melhore a inserção do trabalhador na relação capital-trabalho.

Se para pós-keynesianos o investimento é a decisão mais importante, porque aumenta renda e emprego de forma multiplicada, para os marxistas, apesar da exploração, o emprego é fundamental para a inserção social do trabalhador no capitalismo. O desemprego, além de negar ao trabalhador a inserção social, reduz o seu poder de barganha e os salários, e reduz o seu poder de organização como classe, como vimos acima, e assim tende a piorar, a médio e longo prazos, a própria posição do trabalhador na relação capital-trabalho.

Finalmente, mas não menos importante, o mercado não conduz ao equilíbrio de pleno emprego para os pós-keynesianos, o que justifica uma ação do Estado. Isso porque o investimento, para eles, depende da rentabilidade marginal do capital (eficiência marginal do capital) ser superior ao custo do investimento (a taxa de juros). A eficiência marginal do capital, porém, não pode ser calculada, e é fruto de conjecturas dos investidores sobre o que ocorrerá no futuro, dependendo de fatores incertos não probabilizáveis. Quanto à taxa de juros, depende da oferta e da de- 
manda de moeda, que por sua vez dependem das preferências pela liquidez de bancos e público em geral, o que também se relaciona com a incerteza tal como é percebida por eles. Assim, o investimento é, para os pós-keynesianos, uma variável volátil, o que explica que a instabilidade da renda e do emprego seja um fato normal no capitalismo. É isso que os faz prescrever a ação do Estado, seja via política monetária, baixando a taxa de juros, seja via política fiscal, via gastos em investimentos públicos. No primeiro caso, espera-se que a queda da taxa de juros faça com que mais investidores decidam investir. Entretanto, é possível que a eficiência marginal do capital continue mais baixa do que a taxa de juros, o que abre espaço para a política fiscal. Nesse caso, o governo investe ele mesmo, já que não tem objetivo de lucro, para assim fazendo modificar o ambiente e tornar otimistas as perspectivas empresariais, estimulando então o investimento privado e o crescimento. É então a incerteza que conduz o Estado a ter um papel para garantir aumento da renda e do emprego para os pós-keynesianos.

Para os marxistas, porém, a crítica ao mercado é mais contundente. Ela passa pela ideia de falta de consciência da sociedade quanto à divisão social do trabalho quando ela, como é o caso no capitalismo, é feita por meio de uma coisa, o dinheiro, e se impõe como regra aos participantes da sociedade. No capitalismo os trabalhos são realizados de forma privada, aparentemente independentes uns dos outros, mas todos são compradores e para isso precisam vender, o que impõe uma dependência recíproca. É por meio da venda, ou do dinheiro, no momento dela, que essa dependência recíproca se explicita, porque é pela conversão ou metamorfose das mercadorias em dinheiro no capitalismo que os trabalhos privados recebem validação social, e é dessa forma que o dinheiro insere socialmente todas as classes: o capitalista, vendendo as mercadorias produzidas sob o seu controle; e o trabalhador, vendendo sua força de trabalho; assim como todos os participantes da sociedade, uma vez que todos são necessariamente compradores e, para isso precisam vender algo. É o dinheiro, na venda, que realiza, portanto, a divisão social do trabalho e por isso é que Marx diz que ele é uma relação social no capitalismo.

A análise de Marx do início de O Capital, mas especialmente do dinheiro, nos Grundrisse, é bastante crítica a respeito desse papel do dinheiro na divisão social do trabalho e da importância e do poder social que ele adquire em função disso. Diz Marx sobre isso que, "ele [o dinheiro] só pode possuir uma propriedade social porque os indivíduos alienaram sua própria relação social, fazendo dela um objeto" (Marx, Grundrisse. p. 96, grifo nosso). Deixa claro, aí, que a relação monetária do mundo das mercadorias como relação "recíproca de indivíduos como poderio acima dos indivíduos, tornada autônoma [...] é o resultado necessário de que o ponto de partida não é o indivíduo social livre"(Marx, Grundrisse p. 135), como deveria ser na sociedade transformada.

Esse tipo de análise é que leva Postone (1995) a dizer que enquanto em outras formações sociais pré-capitalistas as relações entre as pessoas são de dependência pessoal, no capitalismo observa-se uma liberdade pessoal dos indivíduos que, no entanto, estão sujeitos a uma "dependência objetiva" imposta pelo contexto social. É essa dependência que para Marx é discutível, por fugir da vontade pessoal, cons- 
ciente, e aparecer como imposição externa, sendo esta uma crítica importante que Marx faz do capitalismo.

Ora, essa importância do dinheiro vista acima faz do mercado o canal de escuta privilegiado no capitalismo. É por meio do mercado que se percebe quem quer e quem pode comprar, quanto quer e quanto pode fazê-lo, é por meio dele que se estabelecem as relações de poder, é participando mais ou menos do mercado que se vive mais e melhor no capitalismo.

Para os marxistas, em particular os críticos do caráter mercantil do capitalismo, é preciso, por isso, criar canais de escuta e expressão alternativos para evitar, justamente, o caráter autônomo e impositivo que as regras de mercado têm sobre a forma de inserção social, a vida, e as relações recíprocas dos indivíduos nesse tipo de sociedade. Isso mostra que é preciso buscar alternativas ao canal do mercado como canal de escuta privilegiado no capitalismo de forma a fazer valer a liberdade social dos indivíduos e seu arbítrio sobre o que construir como sociedade. É sobre essa criação de canais de escuta, pressão, participação e decisão que falaremos no próximo item, sempre buscando transformar a sociedade.

\section{COMO CONSTRUIR ALTERNATIVAS MARXISTAS AO LONGO DO DESENVOLVIMENTO}

Coerente com a frase de Marx anteriormente citada, que vê o socialismo se desenvolver a partir de mudanças no capitalismo, e com Rosdolsky (2001) que, ao analisar o capitalismo, procura perceber os elementos que conteriam características da nova sociedade, ou "os germes da nova formação na história vivida" e nas tendências evolutivas, e com de Paula (2003, p. 150) que, na mesma linha, analisa as "virtualidades emancipatórias" das cidades no capitalismo, Albuquerque (2012) discorre sobre o que chama os "germes visíveis" do socialismo.

Segundo ele (Albuquerque, 2012, pp. 216-7), trata-se de "arranjos institucionais que se desenvolvem ao longo da história do capitalismo", [...] que "não se confundem com o Estado ou com suas transformações estruturais", e "são resultado de lutas sociais, de forças fortemente emancipatórias ou de elementos intrinsecamente comunitários incrustados nesses arranjos institucionais", havendo nesses 'germes visíveis' "uma base para uma nova sociabilidade, alternativa à sociabilidade imposta pelo capital.

A nosso ver, mais que identificar, é possível se criar ou estimular o aparecimento ou mesmo construir essas "virtualidades emancipatórias" (Paula, 2003), e os "germes visíveis" (Albuquerque, 2012) e, mais que isso, é necessário que se o faça, ou que se promova o aparecimento dos mesmos. Discutir algumas formas de facilitar ou estimular tal construção é o objetivo deste item, pensando uma sociedade mais democrática, mais igualitária e menos excludente.

Em livro recente Coutinho (2011) nos deixou uma bela análise da democracia, a partir de Rousseau, Hegel, Marx e Gramsci. Destaca aí ideia de "vontade geral” (interesse comum) de Rousseau, distinguindo-a da vontade de todos, que é a mera 
soma de vontades particulares, e associa tal vontade geral ao "interesse universal" de Marx na Crítica à Filosofia do Direito de Hegel (Marx, 2011).

A posição de Marx, sabemos, é diferente da de Rousseau, para quem a vontade geral é uma questão moral ou fruto da repressão do privado pelo público. Também é diferente da de Hegel, para quem há certo espontaneismo, uma vez que fala em "um movimento dialético pelo qual cada um, ao ganhar, produzir e fruir para si, precisamente por isso produz e ganha para a fruição de todos. Essa necessidade [...] se encontra no encadeamento universal da dependência de todos" (Hegel, 1995, $\$ 199$, p. 353, apud. Coutinho, 2011, pp. 45-6). De fato, para Marx é preciso transformar as bases da sociedade capitalista para poder construir a "vontade geral", ou um sistema onde "o livre desenvolvimento de cada um é a condição para o desenvolvimento livre de todos" (Marx, 2010, p. 45).

A construção da "vontade geral", ou do "interesse universal" requer, porém, que se melhore as condições da sociedade, porque para Marx, como lembra também Coutinho (2011), a vontade geral ou o interesse universal não pode ser construída em condições adversas.

Assim, nesse processo de transformação destacam-se aqui três sugestões certamente não exaustivas para a melhoria das condições da sociedade, caminhando na direção da sua transformação em, de fato, democrática. A primeira, já mencionada anteriormente, é a da criação de canais de escuta alternativos ao mercado; a segunda é a de buscar a igualdade não apenas de renda, mas de consumo e de decisão dentro da sociedade atual; e a terceira é treinar a sociedade para a autogestão.

\section{Buscando canais de escuta}

De forma a transformar a sociedade na direção desejada, dando a todos a possibilidade de opinar, ao contrário do que ocorre com o mercado como escuta, que ouve quem tem recursos para oferecer e para demandar e quanto mais os tenha, e de forma a garantir uma sociabilidade consciente, é preciso achar canais alternativos ao mercado para escutar. A escuta, por sua vez, é condição fundamental para que a sociedade tenha formas institucionais de pressão e participação e para envolver todos nas decisões.

Por maior que seja a importância e o interesse em conceber e usar políticas públicas que melhorem a inserção do trabalhador na relação capital-trabalho, o próprio papel de concepção e de implementação e gestão dessas políticas requer participação mais ampla da sociedade, para que ela se manifeste de forma consciente, ao contrário do que ocorre no mercado e com o dinheiro, ao dividir o trabalho e inserir socialmente as classes no capitalismo. Assim, a criação de canais de escuta estruturados é fundamental se o que se quer é criar condições para o desenvolvimento da vontade geral ou para construir coletivamente tal vontade geral ou o interesse universal.

Não apenas é preciso criar formas de ouvir, mas é preciso construir formas dessa escuta redundar em medidas novas ou alterações de antigas medidas e processos, de forma a colocar em prática o escutado. Trata-se de canais que funcionem 
no dia a dia regularmente, ou sua implementação não cumprirá seu principal papel, que é o de, conduzindo a ação do Estado, transformar a sociedade na direção desejada.

Nesse processo de criação de canais de escuta, que são ao mesmo tempo de pressão, participação e decisão, os conselhos e fóruns comunitários são importantes, assim como todos os processos de democracia participativa. As iniciativas já existentes do tipo orçamento ou planejamento participativo, ou gestão compartilhada de políticas públicas, assim como os empreendimentos privados de economia solidária, que definem e impõem regras coletivas, cumprem já esse papel de canais de escuta e participação, mas é preciso ampliar a frequência com que ocorrem e a amplitude das decisões que são tomadas a partir dessas escutas.

Nesse sentido é preciso destacar o potencial que têm hoje as tecnologias de informação e comunicação, em particular a internet e as redes sociais, embora chamando a atenção, ao mesmo tempo, para os seus limites. Por um lado, como destaca Castells (2007), movimentos sociais podem intervir mais decisivamente nesse tipo de espaço de comunicação. Por outro lado, porém, embora esse seja um espaço de comunicação horizontal e, nesse sentido, mais democrático, ele sofre sempre pressões da lógica do sistema capitalista e pode ser absorvido por ela. Além disso, as mesmas redes sociais que permitem organizar os movimentos sociais podem dar lugar, e o têm feito, a demandas privadas meramente pontuais, desenvolvendo, ao contrário, o individualismo, ao invés da organização coletiva de projetos de transformação efetiva da sociedade (Saad-Filho, 2014).

Assim, a internet e as redes sociais precisam ser vistas apenas como espaço moderno passível de ser usado para desenvolver novos canais de escuta, mas, como todo espaço no capitalismo, sujeito a lutas entre o poder constituído e o contra poder, lutas que podem dar lugar a vitórias meramente transitórias, mas também na direção de mudanças substanciais da sociedade.

Finalmente, até o momento a tecnologia e as redes sociais vêm adensando as relações, em certos casos melhorando a organização em torno de objetivos comuns, mas vêm desenvolvendo, sobretudo, a comunicação no sentido de abrir horizontalmente os canais de fala ou de expressão dos indivíduos. Nossa proposta é que a tecnologia moderna seja usada na busca de ampliação dos canais de escuta da sociedade, canais alternativos aos do mercado. $\mathrm{E}$ isso porque, se, como vem sendo defendido neste artigo, o desenvolvimentismo requer uma ação deliberada do Estado para garantir o desenvolvimento, tal deliberação, do ponto de vista marxista, precisa contemplar a provisão de canais de escuta alternativos ao do mercado, usando inclusive as facilidades oferecidas pelas novas tecnologias de informação e comunicação.

Mais do que simples escutas de demandas da sociedade, os canais de escuta aqui propostos são formas de alterar o controle sobre a organização da sociedade, dando às pessoas consciência e poder de decisão de suas vidas. 


\section{Construindo a igualdade social}

O interesse universal só pode ser construído quando os interesses particulares se tornarem comuns. Daí por que, para Marx, a ditadura do proletariado, ou o sistema sem classes, conduz ao interesse universal. Uma vez que todos têm posição semelhante na sociedade, os interesses particulares são comuns a todos e constituem, portanto, o interesse universal.

A busca desse interesse universal pressupõe, pois, maior igualdade, de forma a aproximar os interesses particulares. Daí a necessidade de construir uma sociedade mais igualitária mesmo no interior do capitalismo. A igualdade precisa ser construída em todos os níveis, seja de renda, forma mais conhecida e discutida, seja de consumo, e de poder de decisão.

Quanto à maior igualdade de renda, não apenas deve ser buscada por meio de tributos e de instrumentos de transferência direta e distribuição dela, mas esse processo pode ser grandemente estimulado quando o desenvolvimento pressupõe como força motora a demanda interna e esta está condicionada a crescimento das rendas mais baixas. Além disso, a geração de emprego e renda pode ser potencializada caso se persiga crescimento industrial privilegiando os setores com maiores efeitos de encadeamento e maiores potenciais geradores de emprego e de renda, razão pela qual nos colocamos do lado do chamado desenvolvimentismo social (Bielschowsky, 2012).

No que se refere ao consumo, Gouverneur (2006) define três tipos de bens e serviços: os individualizados, que seriam os bens e serviços pessoais adquiridos com rendimento próprio; os solidários, ou seja, pessoais, financiados por contribuições para a seguridade social, como é o caso do BPC, e do Bolsa Família; e os bens e serviços coletivizados, que seriam de consumo coletivo financiados por impostos. Nessa última categoria entrariam educação, transporte, saúde, habitação, cultura e lazer, assim como quaisquer outros bens e serviços cujo consumo seja coletivo ou universalizado.

A estratégia marxista ou para uma sociedade democrática, nos termos de Gouverneur (2006), deveria evoluir na direção de maior proporção de bens solidários e, principalmente, coletivizados. Por um lado, essa estratégia garantiria maior qualidade de tais bens e serviços, uma vez que seriam consumidos de forma geral ou universal, havendo pressão dos que mais formam opinião no sentido de garantir-lhes qualidade elevada. Por outro, o consumo coletivo aproxima as situações materiais das pessoas, reduzindo a desigualdade não apenas pelo lado da renda, almejada tanto por marxistas quanto por desenvolvimentistas, mas também pelo lado do consumo.

Uma estrutura econômica e social mais igualitária, finalmente, aproxima os interesses particulares, torna-os mais homogêneos, facilitando decisões onde estão envolvidos acordos mais amplos e, sobretudo, facilitando a construção do interesse universal. Como afirma Devine (2012, p. 218), “[...] a consciência individual é moldada pelo contexto social. A democracia participativa muda ambos, o contexto 
e a consciência". Um contexto mais igualitário interfere na consciência dos problemas comuns e compromete as pessoas na luta pela sua solução, fortalecendo-a.

\section{Treinando a cooperação}

Conforme mencionado anteriormente, a cooperação, por um lado, no processo produtivo, elimina a submissão do trabalhador ao capital no processo de trabalho imediato e a oposição capital-trabalho no processo produtivo dos cooperados. Por outro lado, a cooperação exige de todos participação no processo de planejamento, decisão e gestão dos empreendimentos. Assim fazendo, prepara o futuro da sociedade transformada, uma vez que é um treinamento para a autogestão dos processos produtivos. Finalmente, mesmo quando os processos de produção cooperativos funcionam de forma capitalista ao se relacionarem com outros setores e etapas da economia, comprando insumos ou vendendo mercadorias e serviços, o treinamento cooperativo e a multiplicação de empreendimentos desse tipo é treinamento fundamental para a mudança de lógica de comportamento ainda no interior do próprio capitalismo. Alterna-se ou impõe-se, pelo menos em alguns processos, ou etapas de produção, e mesmo dentro das rotinas de trabalho públicas ou privadas a lógica da cooperação, ao invés da competição que é inerente ao capitalismo. Prepara-se, assim, a sociedade para a transformação.

Como chama a atenção Campbel (2011), a gestão cooperativa exige instituições e práticas diretas e representativas que engajem, de fato, os membros da cooperativa na sua organização. Usando como exemplo a Cooperativa de Mondragon, Campbell refere-se a instituições e práticas como: a) assembleias gerais para analisar práticas passadas e estabelecer guias para o futuro; b) conselhos governamentais para gerir a admissão e a emissão de gerentes e monitorar o dia a dia da gestão; c) conselhos sociais para pensar e conduzir o desenvolvimento dos trabalhadores; $d$ ) integração dos cooperados na gestão formal, como é o caso quando grupos de 10 em cada tarefa escolhem representantes para os conselhos governamentais; e) tanto gestão quanto organização participativas, estimuladas por cultura e formação para a participação; f) formação, especialização e aperfeiçoamento dos membros para a gestão cooperativa. A ideia é garantir: a interação entre gestão direta e representativa de forma a conseguir uma participação autêntica; que a participação na gestão seja mais que mero controle, envolvendo a participação pessoal; e que esses princípios sejam obtidos por meio das instituições e práticas mencionadas. Ora, essas instituições e princípios são específicos em cada caso, dependem de aspectos culturais, regionais e época, e precisam ser treinados. Daí a ideia de disseminar a lógica cooperativa para garantir o progresso nessa direção. Como afirma Devine (2012, p. 258), “a tomada de decisão participativa é transformadora”, porque, ao colocar as pessoas em contato com outros problemas, interesses e argumentos dos demais, incentiva acordos e torna-as interessadas nos bons resultados das decisões tomadas.

Nesse sentido, destacam-se os empreendimentos cooperativos em geral, e de economia solidária em particular, e os projetos de autogestão, mas também, de 
novo, as iniciativas como as do orçamento participativo, dos conselhos, fóruns e comitês de gestão compartilhada, seja das políticas públicas seja das iniciativas privadas. Trata-se de iniciativas que disseminam a lógica cooperativa e isso ajuda a construir a transformação da sociedade. A disseminação dessa lógica é gradativa, e precisa envolver todos porque, como diz Harnecker (2012, p. 165) “o socialismo do século XXI não pode, pois, chegar por uma decisão governamental nem por meio de uma vanguarda iluminada. É um processo que precisa ser construído pelo povo, que, transformando as circunstâncias, transforma-se a si mesmo".

No caso do Brasil, ainda contamos com experiências de economia solidária pontuais e de pequeno porte, funcionando muito mais como soluções transitórias para situações de desemprego ou subemprego, mas com pouca expressão no treinamento efetivo para gestão de processos de produção complexos, com uso de tecnologias modernas e, nesse sentido, pouco adaptados às necessidades atuais.

\section{CONCLUSÃO}

Como bem percebe Gramsci, a economia delimita o âmbito das alternativas ou limita as margens de manobra para a transformação da sociedade. Nesse sentido, não cabe ser voluntarista, achando que é possível mudar apenas por meio de mera decisão política. Mas cabe à política aproveitar as mudanças com a evolução da economia, e a "relação de forças em contínuo movimento e mudança de equilíbrio" (Gramsci, 1999-2002, v. 3, p. 34, apud Coutinho, 2011, p. 128) que caracteriza a realidade efetiva, para transformar, de fato, essa realidade. Evita-se, assim, o determinismo de ver as condições objetivas da economia evoluindo mecanicamente, sem que haja papel ou consequência da subjetividade humana.

Nesse sentido, urge ouvir a vontade coletiva para que ela se imponha, construindo uma sociedade de fato democrática, onde o interesse universal é a norma, ou onde os interesses particulares se confundam com o interesse universal. Para tanto, é preciso não apenas examinar e aproveitar os "germes visíveis do socialismo", ou perceber as "virtualidades emancipatórias", mas também ajudar a construí-los e aprimorá-los.

Analisar tal construção, desenhar seu processo e influir na sua implementação é o que pode e deve fazer a diferença entre desenvolvimentistas e novo-desenvolvimentistas em geral, de um lado, e desenvolvimentistas marxistas, de outro. O desenvolvimentismo deve ser defendido na base da percepção de que o crescimento, ao aumentar o emprego e a renda, melhora a posição do trabalhador na relação capital-trabalho e, assim fazendo, permite que ele se organize para buscar a transformação da sociedade e se prepare para a autogestão da mesma no futuro.

Mas é preciso mais. É necessário criar canais de escuta alternativos ao do mercado, canal por excelência do capitalismo, para ouvir e construir a vontade coletiva ou o interesse universal e envolver toda a sociedade na sua construção, por meio de canais de pressão, participação e decisão. É necessário ainda buscar a igualdade não apenas de renda, mas de possibilidades de consumo e de decisão. 
Quanto maior for a disponibilidade de bens e serviços de uso solidário e principalmente coletivo, mais homogêneos tendem a ser os interesses particulares o que os aproxima do interesse universal. Só assim é possível garantir que a população se prepare para exercer o poder em todos os níveis "promovendo a criação de um novo Estado partindo de baixo, ou um não-Estado que substitua o antigo" (Harnecker, 2012, p. 167).

Finalmente, mas não menos importante, se o canal de mercado e do dinheiro pelo qual ele funciona é criticável, na base da falta de consciência com que divide socialmente o trabalho e com que insere socialmente as pessoas, e na forma impessoal e autônoma com relaciona uns com os outros no capitalismo, pior ainda é a exploração do homem pelo homem que se encontra na base do objetivo de lucro e lucro máximo, que molda os movimentos desse sistema sob a pressão da luta de classes e da concorrência intercapitalista. Cumpre, pois, desenvolver a produção cooperativa, para eliminar no interior do processo de produção a submissão do trabalho ao capital, assim como desenvolver os processos de planejamento, decisão e gestão compartilhados, tanto nas atividades públicas quanto nas privadas, de forma a disseminar a lógica cooperativa contra a competitiva, bem como para treinar todos para a autogestão da sociedade transformada.

\section{REFERÊNCIAS BIBLIOGRÁFICAS}

Albuquerque, E. da M. (2012). Agenda Rosdolsky. Belo Horizonte: Editora UFMG.

Bielschowsky, R. (1988). Pensamento Econômico Brasileiro: o Ciclo Ideológico do Desenvolvimentismo. Rio de Janeiro: IPA/INPES.

Bielschowsky, R. (2001). Anotações sobre a estratégia de crescimento elo mercado interno de consumo popular e o programa do PT para 2003-2006. São Paulo: Instituto da Cidadania, mimeo.

Bielschowsky, R. (Coord.) (2002). Investimento e reforma no Brasil nos anos 1990, cap. 2. Brasília: CEPAL-IPEA.

Bielschowsky, R. (2012). "Estratégia de desenvolvimento e as três frentes de expansão no Brasil: um desenho conceitual”. Economia e Sociedade, v. 21, Número Especial, pp. 729-747.

Bonefeld, W. \& Holloway, J. (1991). Post-Fordism and Social Form: A Marxist Debate on the Post-Fordist State. London: Macmillan.

Bresser-Pereira, L. C. (Org.) (1991). Populismo Econômico: Ortodoxia, Desenvolvimentismo e Populismo na América Latina. São Paulo: Nobel.

Bresser-Pereira, L. C. (2004). “Novo-Desenvolvimentismo”. Folha de S.Paulo, 19 de setembro.

Bresser-Pereira, L. C. (2006). "O Novo Desenvolvimentismo e a Ortodoxia Convencional”. São Paulo em Perspectiva, 20(3): 5-24.

Bresser-Pereira, L. C. (2007). "Estado y Mercado en el Nuevo Desarrollismo”. Nueva Sociedad, 210, Julio-Agosto: 110-125.

Bresser-Pereira, L. C. (2011). "An account of new developmentalism and its structuralist macroeconomics” Revista de Economia Política 31 (3): 493-502.

Brunhoff, S. (1977). “Crise capitalista e política”. In: Poulantzas, N. (ed.). Estado em Crise. Rio de Janeiro: Graal.

Brunhoff, S. (1982). Etat et Capital. Paris: Maspero.

Campbel, A. (2011). "The role of workers in management: The case of Mondragon", Review of Radical Political Economics, November, 9.

Carneiro, R. M. (2006). “O desenvolvimento revisitado”. São Paulo em Perspectiva, v. 20, pp. 73-82. 
Carneiro, R. M. (2012). “Velhos e novos desenvolvimentismos”, Economia e Sociedade, v. 21, Número Especial, p. 749-778, dez..

Castels, M. (2007). "Communication, power and couter-power in the network society”, International Journal of Comunication 1.

Coutinho, C. N. (2011). De Rousseau a Gramsci. São Paulo: Boitempo Editorial.

Clarke, S. (ed.) (1991). The State Debate. London: Macmillan.

Costa, S. (1997). “Movimentos sociais, democratização e a construção de esferas públicas locais”, Revista Brasileira de Ciências Sociais, v. 12, n.35.

Devine, P. (2012a). "Incentives and consciousness". Science \& Society, Vol. 76, No. 2, pp. 215-218.

Devine, P. (2012b).”Social and Long-Term Planning”, Science \& Society, Vol. 76, No. 2, pp. 253-257.

Fiori, J. L. (2011). “A miséria do 'novo desenvolvimentismo””, Carta Maior, 30 de novembro.

Fiori, J. L. (2012a). “O ‘desenvolvimentismo de esquerda”, Carta Maior, 13 de novembro.

Fiori, J. L. (2012b) “Desenvolvimentismo e 'dependência”, Carta Maior, 13 de novembro.

Fonseca, P. C. D. (2004). "Gênese e precursores do desenvolvimentismo no Brasil”. Revista Pesquisa e Debate. São Paulo, PUCSP, 15(2): 225-26.

Frank, A. G. (1973). “Desenvolvimento e subdesenvolvimento latino-americano”. In: Pereira, Luiz (org.). Urbanização e Subdesenvolvimento. Rio de Janeiro: Zahar.

Furtado, C. (1969). "Formação de capital e desenvolvimento econômico”. In: Agarwala, Singh (org.). A Economia do Subdesenvolvimento. Rio de Janeiro: Forense.

Gouverneur, J. (2006). Políticas Económicas Alternativas frente a Crisis y Desempleo, capitalism-and-crisis.info/telechargements/pdf/ES_JG_Políticas_alternativas_juin08_2.pdf.

Harnecker, M. (2012). “Why socialism?”, Science \& Society, Vol. 76, No. 2, pp. 163-167.

Hegel, G. W. F. (1995). Grundliniem der Philosophie des Recht. Frankfurt: Suhrkamp.

Holloway, J. (1991). “The state and every day struggle”. In: Clarke, S. (ed.).The State Debat. London: Macmillan.

Jessop, B. (1991). "Regulation theory, post fordism and the State: more than a reply to Werner Bonefeld". In: Bonefeld, W. \& Holloway, J. Post-Fordism and Social Form: A Marxist Debate on the Post-Fordist State. London: Macmillan.

LEWRG - The London-Edimburgh Weekend Return Group. (1980). In and Against the State. London: Pluto Press.

MARINI, R. M. (1985). Subdesarrollo y revolución. México: Siglo XXI.

Marx, K. (1859 [2008]). Prefácio da Contribuição à Crítica da Economia Política Marx e Engels Obras escolhidas, tomo I. Lisboa: Edições Avante, p. 547.

Marx, K. (2011). Crítica à Filosofia do Direito de Hegel. São Paulo: Boitempo Editorial.

Marx, K. (1974). O Capital, Vol.III. Rio de Janeiro: Civilização Brasileira.

Marx, K. (1980). Manuscrits de 1857-1858 ("Grundrisse”), Paris: Editions Sociales.

Marx, K. \& Engels, F. (2010). O Manifesto Comunista. Rio de Janeiro: Paz e Terra.

Miliband, R. (1973). "Poulantzas and the capitalist state". New Left Review, v. 82, nov./dez.

Mollo, M. L. R. A. (2001). “A concepção marxista de Estado: considerações sobre antigos debates com novas perspectivas”, Economia, ANPEC, volume 2, número 1 - janeiro/junho.

Mollo, M. L. R. (2012). "A concepção marxista de Estado: considerações sobre antigos debates com novas perspectivas”. In: Chitolina, C. L., Pereira, J. A., Oliveira, L. B., e Bordin, R. A, (orgs.), Estado, Indivíduo e Sociedade: Problemas Contemporâneos. Jundiaí: Paco Editorial.

Mollo, M. L. R. \& Fonseca, P. C. D. (2013). "Desenvolvimentismo e Novo-Desenvolvimentismo: raízes teóricas e precisões conceituais”, Revista de Economia Política, v. 33, n. 2 (131), abril-junho.

Paula, J. A. de (2003). "Reino do Capital”, Revista de Economia Política v. 23, n. 4 (92), out-dez.

Postone, M. (1995). "Rethinking Marx (in a post-Marxist World)", Theory Miniconference, "Reclaiming the Arguments of the Founers", $90^{\text {th }}$ Annual Meeting of the American Sociological Association, Washignton, D.C. <http//planeta.clix.pt/obeco/>.

Prebisch, R. (1961). "El falso dilema entre desarrollo económico y estabilidade monetária”. Boletín Económico de America Latina, Vol. VI, n. 1, Santiago de Chile, marzo. Repositório da CEPAL, http://repositorio.cepal.org/bitstream/handle/11362/10070/092_es.pdf?sequence=1 
Poulantzas, N. (1971). Pouvoir Politique et Classes Sociales. Paris: Maspero.

Rosdolsky, R. (2001). Gênese e estrutura de "O Capital" de Marx. Rio de Janeiro: EDUERJ/ Contraponto.

Saad-Filho, A. (2014). "Brazil: development strategies and social change rrom import-substitution to the "events of June"”, Studies in Political Economy, 94, Fall.

Sicsú, J.; Paula, L. F. de; Michel, R. (2005). “Introdução”. In: Novo-Desenvolvimentismo: um Projeto Nacional de Crescimento com Equidade Social. São Paulo: Manole Rio de Janeiro: Fundação Konrad Adenauer. 